\title{
Research on Perceptions of Organizational Politics and Its Influence on Employee Silence
}

\author{
Yiwen Sun, Hongsheng Xia \\ School of Management, Jinan University, Guangzhou, China \\ Email: syw_even12@163.com
}

How to cite this paper: Sun, Y.W. and Xia, H.S. (2018) Research on Perceptions of Organizational Politics and Its Influence on Employee Silence. Open Journal of Business and Management, 6, 250-264.

https://doi.org/10.4236/ojbm.2018.62018

Received: January 12, 2018

Accepted: April 7, 2018

Published: April 10, 2018

Copyright $\odot 2018$ by authors and Scientific Research Publishing Inc. This work is licensed under the Creative Commons Attribution International License (CC BY 4.0).

http://creativecommons.org/licenses/by/4.0/

\begin{abstract}
Perceptions of Organizational Politics and employee silence, as two topics to be avoided in organizations, have long drawn widespread attention in the field of organizational behavior and human resources. Based on the theory of social exchange and the theory of individual-organization fit, this paper aims to explore the relationship between the Perceptions of Organizational Politics and employee silence, as well as the Regulatory effect of Conscientiousness and organizational identification. Firstly, it defines the definitions and dimensions of the four variables (Perceptions of Organizational Politics, employee silence, organizational identity and Conscientiousness) through literature review at home and abroad. Based on the existing research results, this study starts from the social exchange theory and individual-organization fit theory, it constructs a model of the impact of organizational political perception on employees' silence and puts forward hypotheses, in which organizational identification and Conscientiousness are two regulatory variables. Then through a rigorous empirical study to prove the research model proposed in this paper.
\end{abstract}

\section{Keywords}

Perceptions of Organizational Politics, Employee Silence, Organizational Identification, Conscientiousness

\section{Introduction}

Social politics exists in society. Organizational politics also exists, of course. Organizational politics refers to the maximization of self-interest by the members of the organization using the means not recognized by the formal rules of the organization to influence the distribution of benefits within the organization. For example, the phenomena of "defamation", "gossip", and "station team" in the organization are all manifestations of organizational politics. Organizational staff's perception of the political phenomena such as "slander", "gossip" and 
"station team" is called the organization Political Perception (Sun Hanyin, 2004). In the workplace, such phenomena as flattering, defamation and stationing should be ubiquitous in the workplace. If the individual in the workplace is not properly handled, it will be endangered. Therefore, organizational political consciousness is gradually being emphasized by academics, and has become an important issue in the field of organizational behavior and human resource management.

In reality, organizational politics are seldom mentioned by organizational staff. However, when organizational staff perceives that organizational political behavior affects their own interests, organizational staff may take three kinds of behaviors to make up for the losses caused by organizational political behavior. Potential Threats: 1) Participating in organizational politics for personal gain; 2) Avoiding organizational politics and reducing organizational citizenship; 3) Disregarding organizational politics and continuing to give advice and suggestions to the organization. From this we can see that organizational staff's perception of organizational political behavior, that is, organizational political perception, will affect the organizational staff's behavior choices. What this article explores is the influence of organizational political perception on the employee's silent behavior in organizational employee behavior.

The "golden mean" in Chinese society has been a good illustration of the employees' motives for silence. Silence gradually equates in social practice with the reduction of conflicts, the reduction of conflicts with the top members of the organization, and the increase of the recognition has become an effective way to organize the promotion and development of employees. As a result, organizational employees will eventually remain silent as they perceive something that threatens the organization's interests. According to a survey of employee silence reported by the Industrial Weekly in 1991: 849 grassroots management employees from different US organizations participated in the survey, of whom $71 \%$ said their organization did not want to publish their own Organization related comments. Similarly, Ryan and Oestreich (1991) interviewed 260 employees from 22 companies in various regions of the United States. According to the survey, $70 \%$ of employees thought they lacked the courage to expose the problems in the organization [1].

Therefore, the silence of staff has aroused widespread academic attention, but looking at the existing research, the research on the antecedent variables of staff silence has little or no focus on the issue of organizational politics. In addition, based on social exchange theory and individual-organization fit theory, the fit between individuals and organizations is considered to be an important factor that affects employees' attitude and behavior. Organizational identification can be regarded as a concrete manifestation of the fit between individuals and organizations, when the fit between individuals and organizations is high, individuals can be considered to show a high level of organizational identity. High Organization Identity-oriented employees tend to organize interests as the primary 
consideration, in the organization of work is conducive to organizational behavior, therefore, organizational identity affects the relationship between Perceptions of Organizational Politics and employee silence. In the research of individual level, the difference of personality traits of individuals may lead to different perceptions of the same things or events. As a dimension of "Big Five Personality", Conscientiousness is considered by researchers as the most stable personality variable to predict the behavior and attitude of employees [2] [3]. Therefore, the level of responsibility may affect the relationship between Perceptions of Organizational Politics and employee silence Relationship. In summary, through the review of the existing literature, this article attempts to explore the impact mechanism of Perceptions of Organizational Politics on employee silence and the regulatory role played by organizational identity and conscientious personality.

\section{Theoretical Basis}

\subsection{Social Exchange Theory}

The theory of social exchange was first proposed by American sociologist Homans in 1958, and then Blau expanded the theory in 1964. Social exchange theory holds that social exchange behavior includes the exchange of material aspects (remuneration, information, etc.) as well as including non-material aspects (praise, sense of accomplishment, etc.) exchange. If one person has some omissions in the exchange, others are likely to evade the exchange, revealing that social interaction is based on the premise that both parties get each other's returns from each other [4] [5]. Generally speaking, the two parties to the exchange follow the principle of reciprocity, which can be either positive or negative. Putting this exchange relationship into the organization, employees and organizations, employees and colleagues can be regarded as both parties to the exchange, and employees exchange remuneration for the organization with individual work and loyalty to the organization, and the exchange relationship in different cultural backgrounds are established.

According to the theory of social exchange, there are uncertainties and risks in the process of establishing the exchange relationship. Individuals will evaluate the uncertainty and risk in the exchange process. The results of the risk assessment will directly affect people's attitudes and behaviors towards the exchange relationship. Organizational political behaviors existing in the organization are perceived by the employees, which will destroy the exchange relationship between the employees and the organizations and the colleagues, resulting in the employees' passive sabotage and even counterproductive behavior. Research by Kacmar et al. Shows that when political behavior in an organization is prevalent, employees will be cynically cynical, work hard, absent from work, and so on [6]. Research by Ing-Chung Huang et al. Finds that employees who experience dissatisfaction with the organization's political policies and practices can experience ongoing stress and frustration that can cause psychological and physical prob- 
lems such as anxiety, fatigue, depression, The deterioration of interpersonal relationships, these symptoms eventually lead to their indifference to work. Ma et al also pointed out that organizational political cognitive behavior will lead to employee satisfaction with the organization to reduce, triggering a series of negative work behaviors, such as separation, job performance reduction.

Therefore, according to the social exchange theory, employees perceive organizational political behavior, the exchange of staff and organizations have been destroyed, and then lead to employee sabotage behavior, such as employee silence.

\subsection{Individual-Organization Fit Theory}

The concept of individual-organization fit was first proposed by CHATMAN in 1989. He believes that individuals and organizations can influence each other's relationship [7]. Although there are many other factors that can influence the relationship between individuals and organizations, the most basic and longest-lasting is the value. Therefore, he defines the individual-organization fit as the consistency of values between individuals and organizations. O'Reilly's 1992 study of individual-organization fit also clearly defines the fit between individuals and organizations in terms of values, and most definitions now based on this theory apply.

According to the theory of individual-organization fit, both Jansen (2006) and Krist (1996) have pointed out that the fit between individuals and organizations is considered as an important factor that influences the work attitude and behavior of individuals. If individuals and organizations can compare High fit or the need of one individual and one organization can be met by the other's supply, and individuals have higher situational adaptability, which has a positive impact on their working attitude and behavior [8]. Organizational identity can be seen as a concrete manifestation of personal and organizational fit. When employees' values are consistent with organizational values, they maintain a positive working attitude even when they perceive some misconduct in the organization. In addition, Conscientiousness, as a Personality Dimension of the Fifth Personality, is characterized by Conscientiousness, diligence and perseverance, the individual and organizational values of such personality are more likely to be consistent so that the responsible employee demonstrates a higher degree of fit with the organization.

\subsection{Perceptions of Organizational Politics}

Before defining the meaning of organizational political consciousness, we must first understand what constitutes organizational politics. Burns (1961) first proposed the concept of organizational politics as organizing individuals to use their organization for more influence, rights and comfort. Resources undermine the fair competition within the organization's behavior. Ferris et al. (1989) argue that organizational political perception is an activity in which individuals, 
groups, and organizations are committed to the pursuit of self-interest. Organizational members' perceptions and subjective experiences about these activities form the political awareness of organizational members in the organization [9] [10].

The first dimension study of organizational political consciousness was the two-stage study conducted by Ferris (1991), resulting in a five-dimensional structure [9]. However, he later discovered that the five dimensions overlap with the JDI job description indicator subscales, so Ferris again came up with a new five-dimensional structure through further research. In 1992, Ferris and Kacmar merged the organizational five-dimensional structure of political consciousness into a three-dimensional structure, namely: 1) superior behavior; 2) colleagues and small groups; 3) the gap between policy and practice [9]. Based on the Chinese context, our Chinese scholar Ma Chao classifies organizational political perception into three dimensions through exploratory analysis when preparing Perceptions of Organizational Politics scales appropriate to the Chinese context: 1) self-serving behavior; 2) co-worker relationship; 3) remuneration and promotion.

This study combines domestic and foreign research, the organization of political perception is divided into three dimensions: 1) general political awareness; 2) colleagues; 3) salary promotion. The general political perception refers to the individual's perception of the political behavior of the members of the organization to obtain valuable output in the organization in the way of serving themselves. Similar to the self-serving behavior of Ma Chao et al. Ways to get the organization's valuable scarce resources for them. Co-worker relationship refers to the political perception of the exchange of benefits between colleagues in the organization for the best benefit, for example, "colleague and prosper me" among colleagues. Remuneration and promotion refers to the individual's political perception of the organization's actual operational and institutional inconsistency in remuneration and promotion.

\subsection{Employee Silence}

Employee silence, also known as organizational silence, was first proposed by Morrison and Milliken (2000) in a report entitled "Silencing Organizations Barriers to Change and Development in a Diverse World", in which two Scholars define employee silence as a collective phenomenon [11]. Domestic scholar Zheng Xiaotao (2008) defines employee silence as that employees may have come up with ideas, suggestions and perspectives based on their own experience and knowledge, thus improving some aspects of their department or organization. However, for various reasons, they choose to retain opinions or refine Filter your own opinion [11] [12].

\subsection{Organizational Identification}

Organizational identification was first explicitly proposed by March and Simon 
(1958) in the framework of organizational theory research, but for the next few decades there has been limited research on organizational identity. According to Ashforth and Mael (1989), organizational identity is a special form of social identity, an individual's perceived sense of belonging or belonging to the organization [13] [14]. O'Reilly argues that organizational identity is the result of organizational affiliations being attracted and expected by the organization In terms of emotion, while Tajfel defines sociological as organizational self-definition as a result of an individual's identity as a member of the organization, as a result of which membership generates a sense of identity and emotionally Attribution [15].

\subsection{Conscientiousness}

Conscientiousness is one of the dimensions of the Big Five personality, and conscientious personality shows the characteristics of being competent, fair, organized, due diligent, self-disciplined and cautious. The higher the degree of employee responsibility, the more inclined to set high goals for themselves, in a positive way to deal with the frustrations and difficulties encountered in their work [16] [17]. With respect to the definition of accountability, Costa \& McCrae's 1992 study of the Fifth Personality Scale defines liability as: a measure that reflects the individual's diligence, prudence, perseverance, discipline, discipline, and the like. This has also been generally recognized by academics [18].

\section{Research Hypothesis}

\subsection{The Relationship between Perceptions of Organizational Politics and Employee Silence}

According to the theory of social exchange, when the members of the organization perceive that other people in the organization abuse the resources of the organization for the interests of individuals or small groups, and destroy the fair competition among the members of the organization, the exchange relationship between the members and the organizations and colleagues may break down. There are two types of extreme psychology that arise: 1) You want to join the group or do the same for yourself; 2) Disappointment with the organization, which may be manifested in job anxiety, fewer counseling behaviors, and turnover intention (Ferris, 1992). In a 2009 study, Chang pointed out that in an organization where political behavior is prevalent, the relationship between effort, performance and reward becomes vague and uncertain. Employees who are good at flattery, belonging to a small group of companies, and who are close to the top are subject to organizational Reward. This can lead employees to think that their own effort and pay the organization's approval, and employees cannot stand other people's self-interest in the organization, manipulative behavior, resulting in a serious sense of unfairness, deteriorating interpersonal relationships [19]. In order to express dissatisfaction with the political behavior in the organization, employees may respond through a series of anti-production behaviors 
(Ferris, 1996).

Through literature review, we can see that in the domestic research, some scholars conducted empirical research on organizational political behavior and employee silence. When organizational members accomplish organizational goals together, the ultimate benefit distribution is a concern of every member. However, Scarcity of resources and people's growing demand for material benefits, self-interest will appear. When an organization member realizes these self-serving behaviors in an organization, they may choose to be silent for various reasons such as fear of negative feedback or being marginalized by their colleagues (Li et al., 2008). Ma Chao, Ling Wenquan et al. (2006) also made a corresponding empirical study of organizational political perception, confirming that organizational political perception affects employees' work behaviors such as job satisfaction, separation and job performance [20].

Therefore, this study suggests that when organizational members perceive organizational political behavior in organizational activities, such as individuals in organizations using private resources for personal gain or some groups in the organization being promoted and paid for by opaque methods, Because of the balance between individuals and organizations, the exchange relationship is broken, resulting in negative emotions, and then evolved into employee silence. At the same time, when the members of the organization are aware of the behavior of some small groups in the organization, the social exchange relationship between the individual and the colleagues is also broken to some extent. Because of being afraid of negative feedback and getting marginalized by colleagues, the self-protection awareness of the employees is greatly increased Enhance, evolve into employee silence. Therefore, it proposes the following assumptions:

H1: Perceptions of Organizational Politics has a significant positive impact on employee silence;

H1a: General political awareness has a significant positive impact on employee silence;

H1b: Political perception of salary promotion has a significant positive impact on employee silence;

H1c: Political perception of colleague relations has a significant positive impact on employee silence.

\subsection{The Regulatory Role of Organizational Identity}

In the preceding discussion, it has been argued that organizational political perception affects the social exchange relationship between employees and organizations, employees and colleagues, which in turn has an impact on employee silence. The social exchange relations that we have always discussed are just a simple reciprocal relationship. There is also a kind of inter-relationship between employees and organizations, employees and colleagues in addition to the existence of reciprocal relations. Based on the individual-organization fit theory, when personal values are aligned with organizational values, employees view themselves and their organization as a whole, demonstrating a sense of belong- 
ing and pride in the organization. Of course, this can also be extended to individuals and colleagues, and when individuals and colleagues show a high degree of fit, they may show a high degree of identity with colleagues.

Ashforth and Mael's research suggests that employees with high organizational identities will think and act from the values and benefits of the organization. Dick's research also shows that employees with high organizational identities tend to regard themselves as the representatives of the organization, putting the interests of the organization in the most crucial position, making it easier for the organization to have a cooperative attitude and actively representing themselves in the organization and management activities Opinions and opinions This shows that the high recognition of the organization can not only improve the job satisfaction of the members, but also promote the organizational behavior of employees and inhibit the staff's silence. Domestic scholars Li Shumin (2010) and others believe that the organization engaged in the identification of employees will be more likely to internalize the organization's norms, values and interests, the formation of a psychological binding and ownership. The higher the organization's approval, the more it will enhance its own desire for the organization. This means that as employees 'organizational identity increases, their sense of belonging and pride to the organization is higher, and they are more willing to work hard for the development of the organization and make suggestions to reduce the employees' silence [21] [22].

Therefore, It argues that although the reciprocal exchange relationship between employees and organizations is destroyed in the relationship between organizational political perception and employee's silence, employees based on the theory of individual-organization fit and high organization identity will consider the interests of the organization as the starting point This, to a certain extent, supplemented the resource losses suffered by employees during the process of social exchange with the organization. Employees still showed some pro-organizational behavior and employees' silence was reduced. Accordingly, the following assumptions are proposed:

H2: Organizational Identification Negatively Regulates the Relationship between Organizational Political Perception and Staff Silence;

H2a: Organizational identification negatively regulates the relationship between general political perception and employee silence;

H2b: Organizational identification negatively regulates the relationship between political perception of remuneration promotion and employee silence;

H2c: Organizational identification negatively regulates the relationship between political awareness and employee silence regarding co-workers.

\subsection{Responsible for the Regulatory Role}

In the preceding discussion, it has been mentioned that Conscientiousness is a dimension of the Fifth Personality Trait. Individuals with Conscientiousness show diligence, self-discipline, high goals, methodicalness, and confidence. Even in the work experience difficulties or setbacks, will take a positive attitude to deal 
with. Based on the characteristics of conscientious employees, we think the impact of Perceptions of Organizational Politics on employees' silence may vary depending on the degree of employee commitment.

Highly responsible staff has a strong self motivation, a strong sense of self-efficacy, a strong sense of responsibility [18] [23]. When frustrated at work, they will not be discouraged to persevere and will find solutions to the problem. The comprehensive organization of political consciousness can be seen expatiation, when employees perceive organizational politics, may be crowding out by colleagues, unfair feeling, sense of powerlessness and so on, highly responsible employees even in this environment can also be demonstrated to meet the face Self-drive of the problem, frankly speaking, the problems in the organization.

Therefore, it argues that in the relationship between organizational political perception and employees 'silence, the personality traits of employees' self-construal will weaken the relationship. When employees perceive and perceive organizational politics, conscientious personality traits staff will choose to organize their own opinions, to meet their own self-efficacy, sense of responsibility needs.

Accordingly, the following assumptions are proposed:

$\mathrm{H} 3$ : Conscientiousness negatively regulates the relationship between organizational political perception and employee silence;

H3a: Accountability negatively regulates the relationship between general political perception and employee silence;

$\mathrm{H} 3 \mathrm{~b}$ : Conscientiousness negatively regulates the relationship between political perception of remuneration promotion and employee silence;

H3c: Accountability Negatively Regulates the Relationship between Political Perceptions and Co-worker Silence.

\section{Samples and Procedures}

This study mainly uses the form of questionnaires to collect data for research. The questionnaire design contains five parts, the subjects' basic information, Perceptions of Organizational Politics questionnaire, organizational identity questionnaire, responsibility questionnaire and employee silence questionnaire. However, in the selection of the corresponding scale of each variable, it selects the mature scale that has been developed in accordance with the present study after reading and comparing a large number of documents. Due to the fact that some of the scales were developed by foreign scholars, based on the differences between Chinese and Western cultures, it appropriately revised the comprehensive mentors and interviews with these interviews. In addition, pre-investigation of small samples was conducted prior to the formal investigation, the feasibility of the questionnaire was verified through the reliability and validity analysis of small samples, and then further modifications were made to form the final questionnaire for formal investigation.

This study selected employees from Guangzhou, Shenzhen, Shanghai and Hefei to conduct questionnaire survey, we distributes the questionnaire in two 
stages, In the first phase, 70 pre-test questionnaires were distributed through online WeChat, QQ, etc. 66 questionnaires were effectively collected. After the questionnaire was modified through pre-test, the questionnaire was distributed through the second phase, 270 questionnaires were distributed with offline channels, 234 questionnaires were actually collected in one and a half months, and the questionnaire recovery rate was $86.7 \%$. The questionnaires were screened, excluding invalid questionnaires, 211 valid questionnaires were collected, the effective recovery rate of $78.1 \%$. The subjects have a relatively balanced ratio of men and women. The subjects are mostly under 45 years old, of whom $49.8 \%$ are under $25 \%$ and $35.5 \%$ are $26-35$. Education is concentrated in the undergraduate stage, accounting for $65.9 \%$. In the company's position to ordinary staff, $27.5 \%$ of grass-roots managers. The nature of the company where the subjects were located concentrated in private enterprises, state-owned $34.1 \%$, private enterprises $65.9 \%$.

\section{Variable Measurement}

Organizational Politics Perception: This study uses Ma Chao's Organizational Political Perception Scale, combined with the characteristics of it, in Ma Chao original scale was modified, and finally get 12 items of Perceptions of Organizational Politics scale, the use of Li Ke Special 5 points scoring method. Which items 6, 7, 8 using reverse scoring. The total Cronbach's alpha value of the Perceptions of Organizational Politics scale was 0.833 ; the general Cronbach's alpha value of political perception was 0.784 ; the total Cronbach's alpha value of salary promotion was 0.940 ; and the total Cronbach's alpha value of co-worker relationship was 0.841 .

Employee Silence: This study was conducted on the basis of the scale designed by Zheng Xiaotao et al. and was adapted for it. Employee Silence Scale with nine items was obtained, using Likert's 5-point scoring method. The Cronbach's alpha value for this scale is 0.915 .

Organizational identification: It, combined with Chinese context, translates the scale developed by Mael et al. Into Chinese so that the scale is suitable for Chinese enterprises and ultimately obtains 6 items of organizational identity scale, using Rexter 5 Point scoring method. The Cronbach's Alpha of the scale was 0.887 .

Conscientiousness: It extracted 12 short form scales for the Conscientiousness sections of the Big Five personality scales of Costa and McCrae, using Likert's 5-point score from 1 to 5, respectively. Which 3, 7, 9, 10 reverse scoring. The Cronbach's alpha value for this scale is 0.810 .

\section{Data Analysis}

\subsection{Descriptive Statistical Analysis}

The mean of each variable, standard deviation, the correlation coefficient shown in Table 1. 
Table 1. Descriptive statistics.

\begin{tabular}{|c|c|c|c|c|c|c|c|c|c|c|c|c|c|c|}
\hline Variable & Mean & SD & 1 & 2 & 3 & 4 & 5 & 6 & 7 & 8 & 9 & 10 & 11 & 12 \\
\hline Gender & 0.57 & 0.50 & & & & & & & & & & & & \\
\hline Age & 1.69 & 0.83 & $-0.256^{\star *}$ & & & & & & & & & & & \\
\hline Education & 2.95 & 0.73 & 0.096 & $-0.202^{* *}$ & & & & & & & & & & \\
\hline Work years & 1.66 & 0.98 & $-0.222^{* *}$ & $0.738^{* *}$ & $-0.360^{* *}$ & & & & & & & & & \\
\hline Position & 0.56 & 0.50 & 0.133 & $-0.321^{\star *}$ & 0.015 & $-0.374^{\star \star}$ & & & & & & & & \\
\hline Company type & 0.34 & 0.48 & $-0.140^{*}$ & $0.257^{* *}$ & 0.038 & $0.197^{* *}$ & $-0.166^{*}$ & & & & & & & \\
\hline Company size & 2.31 & 1.13 & $-0.135^{\star}$ & 0.087 & $0.188^{* *}$ & 0.124 & $-0.181^{* *}$ & $0.220^{* *}$ & & & & & & \\
\hline $\begin{array}{c}\text { General political } \\
\text { awareness }\end{array}$ & 3.47 & 0.73 & -0.098 & 0.131 & -0.033 & $0.156^{*}$ & -0.069 & $0.150^{*}$ & -0.098 & & & & & \\
\hline $\begin{array}{l}\text { Remuneration and } \\
\text { promotion }\end{array}$ & 2.48 & 0.81 & 0.073 & -0.050 & -0.014 & -0.079 & 0.131 & -0.017 & -0.066 & $-0.160^{*}$ & & & & \\
\hline Co-worker relationship & 3.16 & 0.86 & 0.004 & 0.017 & $-0.177^{*}$ & 0.062 & -0.031 & 0.073 & $-0.146^{*}$ & $0.689^{* *}$ & -0.008 & & & \\
\hline $\begin{array}{l}\text { Organizational } \\
\text { identification }\end{array}$ & 3.82 & 0.73 & -0.085 & 0.065 & $0.190^{* *}$ & -0.006 & -0.063 & -0.009 & 0.049 & $0.141^{\star}$ & $-0.553^{\star *}$ & -0.098 & & \\
\hline Conscientiousness & 3.75 & 0.50 & -0.133 & $0.201^{\star *}$ & $0.172^{\star}$ & 0.073 & 0.029 & 0.002 & 0.064 & 0.127 & $-0.258^{\star *}$ & $-0.159^{\star}$ & $0.456^{* *}$ & \\
\hline Employee silence & 3.03 & 0.77 & 0.066 & 0.017 & $-0.136^{\star}$ & 0.075 & 0.007 & $0.151^{\star}$ & -0.118 & $0.513^{* *}$ & $0.173^{*}$ & $0.638^{\star *}$ & $-0.273^{* *}$ & $-0.263^{* *}$ \\
\hline
\end{tabular}

Note: ${ }^{*}$ Significantly correlated at 0.01 level (bilateral); ${ }^{*}$ Significantly correlated at 0.05 level (bilateral).

\subsection{Hypothesis Testing}

\subsubsection{The Main Effect Test}

The use of Smart-PLS and SPSS to test the hypothesis, the main effect test results. In the present study, population variables such as gender, age and job position were used as control variables. Independent variables were the three dimensions of organizational political perception: general Perceptions of Organizational Politics, perceived salary promotion and peer relationship perception. The outcome variable was employee silence.

Regression analysis of general organizational political perception and employee silence yields model 2 with a coefficient of 0.567 and can pass the two-way test at $\mathrm{P}<0.001$ to achieve significant levels of the equation, so suppose $\mathrm{H} 1 \mathrm{a}$ is supported. The regression analysis of remuneration promotion awareness and employee silence obtained Model 3 with a coefficient of 0.523 and passed the test of $\mathrm{P}<0.001$, with a significant level of the equation. Therefore, H1b is assumed to be supported. Co-worker relationship perception and staff silence were analyzed by regression analysis, and the model 4 , coefficient of 0.714 , and can pass the two-way test at $\mathrm{P}<0.001$, the equation reached a significant level, therefore, it is assumed that $\mathrm{H} 1 \mathrm{c}$ is supported.

\subsubsection{Regulation Effect Test}

1) Test of Organizational Identity Adjustment Effect: For the regulatory role of organizational identity in organizational political perception and em- 
ployee silence, we first conduct a regression analysis on the roles of general political consciousness, salary promotion awareness, co-worker relationship perception and employee silence, respectively, and then introduce Organizational identity and interaction between general political awareness and organizational identity, interaction between salary promotion perception and organizational identity, interaction between colleague relationship and organizational identity to the regression equation to get the research results.

First of all, we analyze the influence of organizational identity on the relationship between general political perception and employee's silence, that is, model 6 , we can see that the coefficient of interaction is -0.122 and is significant at $\mathrm{P}<0.001$, thus confirming Hypothesis $\mathrm{H} 2 \mathrm{a}$; It can be seen from the model 10 that we can see that the interactive item that recognizes the co-worker relationship with the organization identity After introducing the regression equation, the coefficient of the interaction term was -0.104 and passed the significance test at $\mathrm{P}<0.001$, thus supporting the hypothesis $\mathrm{H} 2 \mathrm{c}$.

2) Dutifulness Adjustment Effect Test: For the dutiful adjustment effect test, the interactive items of responsibility and independent variables are included in the regression equation to obtain the research results.

The impact of Conscientiousness on general political perception and employee silence, model 6 , shows that the coefficient of the interaction term is -0.103 and is significant at $\mathrm{P}<0.05$, thus confirming the hypothesis $\mathrm{H} 3 \mathrm{a}$; as can be seen in Model 8, The interaction between salary promotion awareness and Conscientiousness was introduced into the regression equation and the coefficient was -0.215 and passed the significance test with $\mathrm{P}<0.01$, thus supporting the hypothesis H3b; as can be seen in Model 10, the interaction between co-workers and Conscientiousness When the term was introduced into the regression equation, the coefficient of the interaction term was -0.073 and passed the significance test with $\mathrm{P}<0.01$, thus supporting the hypothesis $\mathrm{H} 3 \mathrm{c}$.

\section{Results Discussion}

Organizational awareness of politics has a significant positive impact on employee silence, a conclusion that is consistent with most of the existing research, such as Ferris (1996), CHANG (2009), Li Zhiqiang (2008), Ma Chao et al. (2006) Confirmed that when employees perceive organizational politics, will lead to employee satisfaction, job anxiety, self-protection awareness increases and other activities, employees will actively adjust their work status, the adjustment process there, such as silence behavior, Separation or anti-production behavior.

According to the individual-organization fit theory, when employees recognize organizational culture and organizational values, the organization's interests are taken as the starting point for their own priorities. Therefore, employees perceive Perceptions of Organizational Politics, such as workplace self-interest behavior, Baotuan behavior, high organizational identity of the staff will be based on the interests of the organization as the primary starting point for the organi- 
zation's development to provide advice to eliminate the silent behavior. However, there is no obvious reason for the organizational mediation between pay promotion and employee silence: the cultural background based on Chinese characteristics, when interests are related to money or career, that is, employees perceive aspects of pay and promotions in the organization Unfairness and organizational identity do not eliminate the sense of unfairness perceived by employees. Even if employees have a very high degree of organizational approval, they feel disappointed with the organization, and then remain silent about the problems seen in the organization.

Conscientiousness refers to the individual's personality traits that are rigorous, diligent, high self-efficacy, and high-goal pursuits. When employees feel personality traits such as high responsibility, they perceive self-interest in the workplace (general political awareness), Salary promotion unreasonable behavior (pay promotion political awareness), co-workers indifference, exclusion behavior (co-worker relationship perception), highly conscientious staff will attempt to improve their organization and satisfaction Self-efficacy, and based on the rigorous and diligent personality traits of their own work, they will adopt a positive attitude to constantly adapt and improve the organizational environment in the face of the negative situation (organizational politics) in the organization. However, when low-responsibility employees perceive organizational politics, they can turn a blind eye to the problems in the organization and exacerbate their silent behaviors.

\section{Conclusions}

Domestic and foreign scholars have studied organizational politics perceptions and found that organizational political perception has many impacts on employees' work behaviors. However, organizational politics and employee silence are highly secretive (Sun Hanyin, 2006) different understanding. Therefore, the current research shows how organizational political perception affects employee silence. This study examines the impact of organizational political perception on employee silence from two levels of organizational identity (organizational level) and Conscientiousness (individual level) variables, and complements the research of employee silence and organizational political perception. In addition, Ridetta's (2005) study of organizational identity verifies that organizational identity is a very important predictor of employee organizational citizenship, and that employees with high organizational identities generate a "mastership" in the organization [24]. Yan Dan and Huang Peilun (2012) studied employee suggestions from the perspective of organizational identity, and verified that organizational identity plays an influential role in employee suggestions. Therefore, it extracts organizational identity as a variable at the organizational level to explore the relationship between Perceptions of Organizational Politics and employee silence. This certainly complements the existing research in this area.

Through the study of this article, we can deeply understand that the mechan- 
ism of organizational politics perception and its mechanism will help organizations and employees take preventive and control measures to eliminate or mitigate the negative influence of organizational political consciousness. In addition, through two levels of regulatory variables to explore, but it is also for enterprises to establish their own organizational culture and to attract talent to provide a reference.

Due to the special features of this study, in the future research, especially in the initial stage of exploring the influencing factors of employee's silence, future researchers should consider non-traditional research methods such as projection technology and mutual evaluation of upper and lower levels. And, more importantly, follow-up researchers should use these measurement tools in combination to minimize the common methodological bias associated with the impact of social subjectivity, and then accurate measurement of variables such as organizational political awareness and employee silence.

\section{References}

[1] Dyne, L.V., Ang, S. and Botero, I.C. (2003) Conceptualizing Employee Silence and Employee Voice as Multidimensional Constructs. Journal of Management Studies, 40, 1359-1392. https://doi.org/10.1111/1467-6486.00384

[2] Lalwani, A.K. Shavitt, S. (2013) You Get What You Pay for? Self-Construal Influences Price Quality Judgments. Journal of Consumer Research, 40, 255-267. https://doi.org/10.1086/670034

[3] Brockner, J., Chen, Y.R., Mannix, E.A., Leung, K. and Skarlicki, D.P. (2000) Culture and Procedural Fairness: When the Effects of What You Do Depend on How You Do It. Administrative Science Quarterly, 45, 138-159. https://doi.org/10.2307/2666982

[4] Blau, P. (1964) Exchange and Power in Social Life. John Wiley \& Sons, New York.

[5] Homans, G.C. (1958) Social Behavior as Exchange. American Journal of Sociology, 1958, 597-606. https://doi.org/10.1086/222355

[6] Kacmar, K.M. and Baron, R.A. (1999) Organizational Politics: The State of the Field, Links to Related Processes, and an Agenda for Future Research. Ferris Gerald. Research in Human Resources Management, 17, 1-39.

[7] Chatman, J.A. (1989) Improving Interactional Organizational Research: A Model of Person-Organization Fit. Academy of Management Review, 14, 333-349.

[8] Jansen, K.J. and Kristof-Brown, A. (2006) Toward a Multidimensional Theory of Person-Environment Fit. Journal of Managerial Issues, 18, 193-212.

[9] Ferris, G.R. and Kacmar, K.M. (1992) Perceptions of Organizational Politics. Journal of Management, 18, 93-116. https://doi.org/10.1177/014920639201800107

[10] Ferris, G.R., Russ, G.S. and Fandt, P.M. (1989) Politics in Organizations. Impression Management in the Organization, 1989, 143-170.

[11] Morrison, E.W. and Milliken, F.J. (2000) Organizational Silence: A Barrier to Change and Development in a Pluralistic World. Academy of Management Review, 25, 706-725.

[12] Edmondson, A.C. (2003) Speaking up in the Operating Room: How Team Leaders Promote Learning in Interdisciplinary Action Teams. Journal of Management Studies, 40, 1419-1452. https://doi.org/10.1111/1467-6486.00386 
[13] Ashforth, B.E. and Mael, F. (1989) Social Identity Theory and the Organization. The Academy of Management Review, 14, 20-39.

[14] Mael, F.A. and Ashforth, B.E. (1992) Alumni and Their Alma Mater: A Partial Test of the Reformulated Model of Organizational Identification. Journal of Organizational Behavior, 13, 103-123. https://doi.org/10.1002/job.4030130202

[15] Elliot, A.J. and Devine, P.G. (1994) On the Motivational Nature of Cognitive Dissonance: Dissonance as Psychological Discomfort. Journal of Personality and Social Psychology, 67, 382-394. https://doi.org/10.1037/0022-3514.67.3.382

[16] Greenbaum, R.L., Mawritz, M.B. and Eissa, G. (2012) Bottom-Line Mentality as an Antecedent of Social Undermining and the Moderating Roles of Core Self-Evaluations and Conscientiousness. Journal of Applied Psychology, 97, 343-359. https://doi.org/10.1037/a0025217

[17] Lu, L. and Gilmour, R. (2007) Developing a New Measure of in Dependent and Interdependent Views of the Self. Journal of Research in Personality, 41, 249-257. https://doi.org/10.1016/j.jrp.2006.09.005

[18] Costa, P.T. and McCrae, R.R. (1992) Revised NEO Personality Inventory (NEO PI-R) and NEO Five-Factor Inventory (NEO-FFI): Professional Manual. Psychological Assessment Resources, Odessa, FL.

[19] Bowen, F. and Blackmon, K. (2003) Spirals of Silence: The Dynamic Effects of Diversity on Organizational Voice. Journal of Management Studies, 40, 1393-1417. https://doi.org/10.1111/1467-6486.00385

[20] Pinder, G. and Harlos, H.P. (2001) Employee Silence: Quiescenee and Acquiescence as Responses to Perceived Injustice. Research in Personnel and Human Resource Management, 20, 331-369. https://doi.org/10.1016/S0742-7301(01)20007-3

[21] Dutton, J.E., Dukerich, J.M. and Harquail, C.V. (1994) Organizational Images and Member Identification. Administrative Science Quarterly, 39, 239-263. https://doi.org/10.2307/2393235

[22] Dutton, J.E. and Dukerch, J.M. (1991) Keeping an Eye on the Mirror: Image and Identity in Organizational Adaptation. The Academy of Management Journal, 34, 517-554.

[23] Oyserman, D. and Markus, H.R. (1998) Self as Social Representation. In: Flick, U., Ed., The Psychology of the Social, Cambridge University Press, New York, 107-125.

[24] Ridetta, M. (2005) Organizational Identification: A Meta-Analysis. Journal of Vocational Behavior, 66, 358-384. https://doi.org/10.1016/j.jvb.2004.05.005 